\title{
Marginal Analysis: An Economic Procedure for Selecting Alternative Technologies/Practices ${ }^{1}$
}

Edward Evans ${ }^{2}$

\section{Introduction}

Many agricultural researchers/extension agents today incorporate some level of economic analysis in decisions concerning the alternative technologies or practices they recommend to agricultural producers for improving income. This is in sharp contrast to the previous two decades when little or no economics were included in the decision-making process. At that time, researchers' recommendations were based solely on increasing yields because they thought producers were only interested in net returns. Today, however, researchers, and those who recommend improved practices to the agricultural community, consider how proposed technologies and their associated risks may impact profitability, and therefore have become involved in the early stages of research planning and analysis.

Within the last two decades, fewer research funds and greater demand for accountability of publicly-funded research have made it imperative for researchers to be more selective in their research by focusing on topics that have the best potential to give the biggest "bang for the buck." At the same time, increased globalization has forced agricultural producers to become more competitive, relying on research institutions such as UF/IFAS (University of Florida's Institute of Food and Agricultural Sciences) to provide them with technologies that meet consumers' demands, satisfy sensitive environmental concerns, increase productivity, give a competitive edge, and are financially viable.

These trends have created the need for a set of tools and procedures which researchers, especially those who do not readily have access to an economist, can employ to assess which practices may be adopted. The purpose of this article is to outline a simple economic procedure, based on the economic principles of marginal analysis, to assist the researchers in decision making. It was made popular at CIMMYT (Perrin, et al., 1988) and is summarized below. CIMMYT is the acronym for Centro Internacional de Mejoramiento de Maiz y Trigo (International Maize and Wheat Improvement Center), located in Mexico.

\section{Defining Marginal Analysis}

Marginal analysis as used within this context is a procedure for calculating marginal rates of return

1. This is EDIS document FE565, a publication of the Department of Food and Resource Economics, Florida Cooperative Extension Service, Institute of Food and Agricultural Sciences, University of Florida, Gainesville, FL. Published June 2005. Please visit the EDIS website at http://edis.ifas.ufl.edu.

2. Edward A. Evans, Assistant Professor, Department of Food and Resource Economics, Tropical Research and Education Center, Homestead, FL, Florida Cooperative Extension Service, Institute of Food and Agricultural Sciences, University of Florida, Gainesville, FL.

The Institute of Food and Agricultural Sciences (IFAS) is an Equal Opportunity Institution authorized to provide research, educational information and other services only to individuals and institutions that function with non-discrimination with respect to race, creed, color, religion, age, disability, sex, sexual orientation, marital status, national origin, political opinions or affiliations. U.S. Department of Agriculture, Cooperative Extension Service, University of Florida, IFAS, Florida A. \& M. University Cooperative Extension Program, and Boards of County Commissioners Cooperating. Larry Arrington, Dean 
between technologies, proceeding in a stepwise manner from a lower-cost technology to the next higher-cost technology, and comparing marginal rates of return to acceptable minimum rates od return (Perrin, et al., 1988). The procedure is useful for making recommendations to producers and for selecting alternative technologies. The economic principle underlying the analysis is that it is worthwhile for a producer to continue investing up to the point where the return from each extra unit invested equals the cost of the extra unit. As applied to a situation in which the producer is confronted with a set of discrete alternative technologies, the producer should invest in the costlier technology as long as the marginal rate of return (in switching from a lower-cost technology to a higher-cost technology) is greater than the minimum acceptable rate of return. Hence, recommending technologies to producers is not based solely on the premise that a technology must be profitable (i.e., added returns are greater than added costs), but that it must also satisfy the added criterion that the marginal rate of return must be above a given minimum acceptable rate of return. Technologies satisfying these criteria stand the greatest chance of being adopted.

\section{Carrying Out Marginal Analysis}

There are several steps in carrying out marginal analysis. The level of complexity in carrying out marginal analysis will vary depending on the nature of the experiment and the level of sophistication employed. For example, consider the researcher who has conducted fertilizer trials using four different rates (40, 80, 120, and 160 pounds) of fertilizer "X" per acre. Assume that the producer is currently using no fertilizers, as indicated by Technology 1 in Table 1. The researcher wishes to get the producer to adopt a technology using fertilizer "X" (applying fertilizer at one of the prescribed rates). The results of the experiment are summarized in Table 1.

\section{Determining Net Benefits}

To determine the "net benefits" of different technologies, the researcher must first calculate the "gross field benefit" and the "total costs that vary" in switching technologies. The gross field benefit for each technology is obtained by multiplying the "adjusted yield" by the farmgate price. The adjusted yield represents a fraction (e.g., 0.9 ) of the average yield the researcher obtained under an experimental condition (one reason for making an adjustment in yield is that the producer, in switching technologies, might not exercise the same level of precision and timeliness as the researcher; therefore, a more conservative estimate is warranted). The farmgate price is the price that the producer receives less any harvesting and marketing costs.

The total costs that vary (total costs) for each technology is the sum of ONLY those costs that are expected to change by using another technology. If a particular technology results in cost savings, then this should be subtracted from the total cost. In certain situations where market prices are not readily available for various inputs, the researcher might need to consult an economist who would be able to estimate the economic (opportunity) cost of the resource.

The net benefit for a given technology is then obtained by subtracting the total cost from the gross field benefit. It should be pointed out that the net benefit is not the same as net profit since it only takes into consideration those costs that vary by switching from one technology to another.

As discussed earlier, the first step is to identify all the variables involved in switching technologies and to compute the gross field benefits (the total cost of each technology after yields have been adjusted downwards, by say 10\%) and the net benefits. This information is summarized in Table 2.

\section{Conducting Dominance Analysis}

Once the net benefit has been determined for each technology, the next step is to perform a dominance analysis. This is done by sorting the technologies, including the current technology the producer is using, on the basis of costs, listing them from the lowest to the highest, together with their respective net benefit. In moving from the lowest to the highest, any technology that costs more than the previous one but yields less net benefits is said to be "dominated" and can be excluded from further analysis. 
Table 3 illustrates how switching technologies increases the total costs. This illustration reveals that Technology 5 is dominated and can be left out of the analysis. By switching from Technology 4 to Technology 5 , the producer would incur an additional cost of $\$ 25$ (\$110 minus $\$ 85$ ) but would realize a loss of net benefits of $\$ 7$ ( $\$ 528$ minus $\$ 535$ ). The fact that Technology 5 has the highest gross yield $(3,544$ pounds) per acre and the highest net benefit (\$638) shows that the costs associated with switching to this new technology were sufficiently high enough not to warrant a switch from Technology 4 (Table 2). Here it may be possible that further research could be carried out on Technology 5 to see if the benefits could be increased or the costs reduced.

\section{Calculating Marginal Rate of Return (MRR)}

Having eliminated all dominated technologies, the marginal rate of return between technologies can be calculated. Proceeding in a stepwise manner, beginning with the lowest-cost technology and the next ascending technology, the marginal rate of return is computed by expressing the difference between the net benefit of the pair as a percentage of the difference of the total cost. The computed marginal rate of return gives an indication of what a producer can expect to receive, on average, by switching technologies. Hence, a 150\% marginal rate of return in switching from Technology 1 to Technology 2 implies that for each dollar invested in the new technology, the producer can expect to recover the $\$ 1$ invested plus an additional return of $\$ 1.50$.

Table 4 illustrates calculating the marginal rate of return between technologies. The figures reveal that the highest rate of return at $287 \%$ (i.e., $\$ 86$ divided by \$30) was obtained in the switch from Technology 1 to Technology 2. However, as will be seen below, this does not necessarily imply that this technology should be recommended.

\section{Determining Minimum Acceptable Rate of Return (MARR)}

Before a given technology is recommended to a producer it is advisable that the researcher know what the producer considers a minimum acceptable rate of return. In general, the more innovative the producer is, the lower the minimum acceptable rate of return will be. Because most producers are comfortable with the technology they are currently using, it usually takes a sizable return to get them to voluntarily switch technologies. Perrin, et al. (1988) provide some general guidelines for determining minimum acceptable rate of return. Without asking producers what they considered to be a reasonable rate of return, researchers noted that experience and empirical evidence suggest that a rate between $50 \%$ and $100 \%$ seems adequate. If the technology is new and requires learning new skills, then the upper-bound should be used. In cases where switching technologies simply represents an adjustment, such as a different fertilizer rate, then the lower-bound may be acceptable. An alternative approach to estimating the minimum rate of return is to double the rate of interest charged by the lending institution.

\section{Comparing MRR with MARR}

As pointed out earlier, the premise is that producers will be willing to switch from one technology to another as long as the marginal rate of return is greater than the minimum acceptable rate of return. The decision rule therefore is to proceed stepwise from the technology with the lowest total cost, and compare the marginal rates of returns in switching from a particular technology to the next higher-cost technology having the minimum acceptable rate of return. Therefore, producers should choose the technology with the highest total cost for which the marginal rate of return is above or equals the minimum acceptable rate of return.

Assume that (based on discussions with producers) it is ascertained that the minimum acceptable rate of return is $100 \%$. By switching from Technology 1 to Technology 2, a producer would do better, and would do even better by switching to Technology 3, since the MRR between Technologies 2 and 3 gives a rate of return above the $100 \%$ acceptable rate of return. Hence, notwithstanding, the fact that a switch from Technology 1 to Technology 2 yields the highest MRR, a producer's overall net income could improve if an additional investment is made to acquire Technology 3 . However, note that by switching from Technology 3 to Technology 4, the 
MRR is only $36 \%$, and while it is profitable in the sense that the added revenue generated by Technology 4 covers the added expense, it would not be wise to recommend this technology, since the rate of return is below what the producer considers to be acceptable. In other words, if a producer were to switch from Technology 3 to Technology 4 , it would mean investing another $\$ 25$ (\$85 minus $\$ 60)$ and obtaining an additional net return of only $\$ 9(\$ 535$ minus $\$ 526$ ), or a return of $36 \%$ on the last $\$ 25$ invested. Hence, the best technology to recommend would be Technology 3. Of course, if a producer's minimum acceptable rate of return were less than $36 \%$, the recommended technology would be Technology 4.

\section{Concluding Remarks}

Economic principles can aid researchers/extension agents in selecting technologies/practices that are the most profitable and have the best chance of being adopted by producers. As the example demonstrates, it is not always the technology that returns the highest yield, net benefit, average return, or marginal return that is the best one to be recommended.

\section{References}

Perrin, R., J. Anderson, D. Winkelmann, and E. Moscardi. 1988. From Agronomic Data to Farmer Recommendations: An Economic Training Manual. CIMMYT: Mexico, D.F. Available online at http://www.cimmyt.org. 
Table 1. Fertilizer experiment data.

\begin{tabular}{|cccc|}
\hline \hline Technology & Fertilizer "X" & "X" Applications & Average Yield \\
\hline & (pounds/acre) & (number) & (pounds/acre) \\
$1^{*}$ & 0 & 0 & 2,222 \\
2 & 40 & 1 & 2,867 \\
3 & 80 & 2 & 3,256 \\
4 & 120 & 2 & 3,444 \\
5 & 160 & 2 & 3,544 \\
\hline $\begin{array}{l}\text { * Current technology being used. } \\
\text { Source: Based on Perrin, et al. (1988). }\end{array}$ & & \\
\hline \hline
\end{tabular}

Table 2. Calculation of net benefits.

\begin{tabular}{|ccccccc|}
\hline \hline & Units & \multicolumn{5}{c}{ Technology } \\
\cline { 2 - 6 } & & $\mathbf{1}$ & $\mathbf{2}$ & $\mathbf{3}$ & $\mathbf{4}$ & $\mathbf{5}$ \\
\hline Average yield & pounds/acre & 2,222 & 2,867 & 3,256 & 3,444 & 3,544 \\
Adjusted Yield & pounds/acre & 2,000 & 2,580 & 2,930 & 3,100 & 3,190 \\
Gross Field Benefits & dollars/acre & $\mathbf{4 0 0}$ & $\mathbf{5 1 6}$ & $\mathbf{5 8 6}$ & $\mathbf{6 2 0}$ & $\mathbf{6 3 8}$ \\
Cost of Fertilizer & dollars/acre & 9 & 25 & 50 & 75 & 100 \\
Cost of Labor & dollars/acre & 0 & 5 & 10 & 10 & 10 \\
Total Costs That Vary & dollars/acre & $\mathbf{0}$ & $\mathbf{3 0}$ & $\mathbf{6 0}$ & $\mathbf{8 5}$ & $\mathbf{1 1 0}$ \\
Net Benefit & dollars/acre & $\mathbf{4 0 0}$ & $\mathbf{4 8 6}$ & $\mathbf{5 2 6}$ & $\mathbf{5 3 5}$ & $\mathbf{5 2 8}$ \\
\hline \hline
\end{tabular}


Table 3. Dominance analysis.

\begin{tabular}{|ccc|}
\hline \hline Technology & Total Costs That Vary & Net Benefits \\
\hline 1 & (dollars/acre) & (dollars/acre) \\
2 & 0 & 400 \\
3 & 30 & 486 \\
4 & 60 & 526 \\
5 & 85 & 535 \\
& 110 & 528 \\
\hline \hline
\end{tabular}

Table 4. Marginal rate of return between technologies.

\begin{tabular}{|ccccccc|}
\hline \hline Technology & \multicolumn{2}{c}{ Total Costs That Vary } & Net Benefits & & \multicolumn{2}{c|}{ Marginal Rate of Return } \\
\hline & (dollars/acre) & (dollars/switch) & (dollars/acre) & (dollars/switch) & $(\%)$ \\
1 & 0 & 0 & 400 & - & - \\
2 & 30 & 30 & 486 & 46 & 287 \\
3 & 60 & 30 & 526 & 9 & 36 \\
4 & 85 & 26 & 535 & & 36 \\
\hline \hline
\end{tabular}

